Section Editors

David C. Spencer, MD

Steven Karceski, MD

Steven Karceski, MD

\title{
New ways to assess brain function in Parkinson disease
}

Over the past 40 years, our understanding of the brain and its function has dramatically changed. Much of this has been due to new ways of looking at the living brain. It was in the 1970s that computed tomography scans (CT or CAT scans) were first used. By the 1980s CAT scans were commonplace. Magnetic resonance imaging (MRI) was developed in the 1980s. It became widely available thereafter and is now a standard way of looking at the brain and other parts of the nervous system. CAT and MRI have allowed scientists to study the structure of the living brain in detail. In addition, doctors and scientists have been able to study neurologic disease in ways that previously were not possible.

CAT and MRI are mostly used to look at brain structure. However, newer MRI techniques have made it possible to look at how the brain functions. One of these techniques is functional MRI (fMRI). fMRI works by studying changes in blood flow. Blood flow increases to regions of the brain that are more active. This makes sense: active parts of the brain use up oxygen. Blood flow increases to these areas in order to bring in the oxygen that is needed. For instance, if a person were performing a language task, the language areas of the brain would need more oxygen. Blood flow to this area would increase and can be measured using fMRI.

When performing specific tasks, many brain regions will be activated. The areas are interconnected in a way to make the tasks faster and more efficient. The connectivity between different brain areas can be studied using fMRI. Even at rest, the brain remains active. fMRI can be used to measure the connectivity between brain regions in the resting state.

Resting-state fMRI has already been used in a variety of medical illnesses and has helped scientists to better understand illnesses such as autism, attention deficit disorders, epilepsy, Alzheimer disease, and Parkinson disease (PD). Resting-state $\mathrm{AMRI}$ is mostly experimental. However, as more is learned, it may become a valuable tool in the diagnosis of many neurologic illnesses. In addition, resting-state fMRI may enable doctors to "see" how a person responds to treatment. In other words, it may offer a way to make treatments more effective.

WHAT DID THE AUTHORS STUDY? In their article "Functional connectivity and cognitive decline over 3 years in Parkinson disease," Dr. Olde Dubbelink and colleagues $^{1}$ used resting-state fMRI to study the brains of people with idiopathic PD. They performed their study at VU University Medical Center in Amsterdam, the Netherlands. They observed how the functional connectivity changed over 3 years in people with PD.

In the past, there have been fMRI studies in PD. These studies mainly looked at the motor system of people with $\mathrm{PD}$. This makes sense as one of the characteristic problems in PD is a slowness to move. In order to better understand problems with thinking that can occur in PD, Dr. Olde Dubbelink and colleagues decided to look at the whole brain. This had never been done. In addition, the scientists looked at changes that occurred over time. This also had not been previously studied.

HOW WAS THE STUDY DONE? In the study, the researchers selected 55 patients with PD. All had been enrolled in another study of PD. They agreed to have fMRI twice, once at the beginning of the study and once 3 years later. The patients were on average 65.8 years old. They had been affected by PD for an average of 9.24 years. Many of them were taking medication(s) for their PD.

Dr. Olde Dubbelink and colleagues compared the fMRI of people with PD to 15 people without PD. The unaffected people were age-matched, meaning that they had the same ages as the people with PD. In addition to the resting fMRI, each person was assessed for motor function. The study assessed movement problems with the Unified Parkinson's Disease Rating Scale (UPDRS-III), a tool that has been widely used and studied. A higher score on the UPDRS-III indicates a greater degree of movement problems. They assessed thinking and cognition with the Cambridge Cognitive Examination (CAMCOG) scale. CAMCOG scores below 80 indicate dementia. The UPDRS-III and CAMCOG were performed over time in order to carefully measure a decline in both motor and cognitive function.

All 55 patients with PD had an fMRI at the beginning. However, only 36 had the second fMRI for comparison. Nineteen patients either dropped out of the study or passed away. Of the 15 controls, 12 had a second fMRI. The fMRIs carefully studied 93 
areas of interest in the brain. In addition, the functional connectivity of these regions was evaluated. First, the people with PD were compared to the unaffected controls. Next, the second fMRI was compared to the first to determine what changes had occurred over a 3-year period of time.

Medications can affect the fMRI. Knowing this, the authors always studied the people with PD when they were taking their medications so that the results would show how their brains were functioning while on medication.

WHAT WERE THE RESULTS? When compared to the controls, the people with PD had moderate movement problems, as measured by their UPDRS-III tests. They also had lower scores on cognitive testing (CAMCOG). As the PD worsened, the movement scores got worse. Similarly, over time the cognitive scores worsened. The resting fMRI showed reduced functional connectivity in people with PD. Over time, the functional connectivity worsened. The functional connectivity worsened in several brain regions, but the greatest change occurred in the posterior (toward the back) regions of the brain.
The researchers then compared the fMRI scores with both the UPDRS-III and the CAMCOG scores. Although both worsened, there was a stronger association between the changes in the fMRI and the cognitive scores (CAMCOG).

WHAT DOES THIS MEAN? This was the first study to assess resting-state functional connectivity in people with PD. Further, it was the first time that someone evaluated how resting-state functional connectivity changes over time. Not only did Dr. Olde Dubbelink and colleagues show that people with PD have decreased functional connectivity compared to unaffected people, they were also able to show a decline over time. The decline correlated more strongly with changes in thinking compared with changes in the ability to move easily. With additional study, fMRI may become a valuable tool to assess and follow people with PD.

\section{REFERENCE}

1. Olde Dubbelink KTE, Schoonheim MM, Deijen JB, Twisk JWR, Barkhof F, Berendse HW. Functional connectivity and cognitive decline over 3 years in Parkinson disease. Neurology 2014;83:2046-2053. 


\section{PATIENT PAGE}

Section Editors

David C. Spencer, MD

Steven Karceski, MD

Steven Karceski, MD

\section{About Parkinson disease}

WHAT IS PARKINSON DISEASE? Parkinson disease (PD) is named after James Parkinson. He first described the illness in 1817. PD mostly causes problems with moving around. It can cause a person to move very slowly, called bradykinesia. A person with PD will often appear stiff or rigid. At times, a person with PD may suddenly "freeze up" or be unable to move for a short period of time.

In $\mathrm{PD}$, a tremor of the hands is common. It is called a "pill-rolling" tremor because of how it looks. Many years ago, pharmacists used to make their own tablets. In order to make the medications into a tablet, they would "roll" the medicine into a small ball. The motion that it takes to roll a small ball looks very similar to the tremor in PD. People with PD often have one or more of these symptoms.

WHAT CAUSES PARKINSON DISEASE? In PD, the underlying problem has to do with a neurotransmitter called dopamine. A small number of very specific brain cells make dopamine. Although only a few cells make dopamine, these cells send the neurotransmitter to many different regions of the brain. Changes in dopamine levels can have widespread effects within the brain.

When we are young, our brains make plenty of dopamine. As we get older, this amount decreases. In PD, the amount of dopamine becomes critically low. The amount of dopamine changes very slowly over time. This causes the very gradual worsening of movement (and a worsening of the tremor).

TREATMENT OF PARKINSON DISEASE Understanding the link between dopamine and PD led to the development of many treatments. The answer seems simple enough: take dopamine. Unfortunately, the body does not allow dopamine to cross over into the brain where it is needed. This is why people with PD take levodopa. Levodopa can cross over into the brain. The brain converts the medication into dopamine.

There are many other treatments for PD. For the most part, these treatments are aimed at increasing the amount of dopamine in the brain. Other treatments help to keep the dopamine where it is needed most. These treatments maintain the levels of dopamine. By keeping the levels constant, these treatments prevent the motor symptoms from returning.

A physician may not know which treatment is best for a specific person. Every person is different. Some people may require only one medication. Others may need 2 or more medicines. Physicians must therefore tailor the treatment to the individual.

Although studies can tell us which medicines work, they do not tell us which ones work best for a specific person. Sometimes more than one medicine must be tried before the best treatment plan can be found. A person with PD can become frustrated if the first treatment does not work. By talking honestly with your doctor, the best treatment can be found.

\section{FOR MORE INFORMATION}

Neurology Now ${ }^{\circledR}$

http://journals.lww.com/neurologynow/Pages/Resource-

Central.aspx

American Parkinson Disease Association

http://www.apdaparkinson.org

The Michael J. Fox Foundation for Parkinson's Research

http://www.michaeljfox.org

National Parkinson Foundation

http://www.parkinson.org 


\title{
Neurology
}

\author{
New ways to assess brain function in Parkinson disease \\ Steven Karceski \\ Neurology 2014;83;e199-e201 \\ DOI 10.1212/WNL.0000000000001091
}

This information is current as of November 24, 2014

\section{Updated Information \&} Services

References

Permissions \& Licensing

Reprints including high resolution figures, can be found at: http://n.neurology.org/content/83/22/e199.full

This article cites 1 articles, 0 of which you can access for free at: http://n.neurology.org/content/83/22/e199.full\#ref-list-1

Information about reproducing this article in parts (figures,tables) or in its entirety can be found online at:

http://www.neurology.org/about/about_the_journal\#permissions

Information about ordering reprints can be found online:

http://n.neurology.org/subscribers/advertise

Neurology ${ }^{\circledR}$ is the official journal of the American Academy of Neurology. Published continuously since 1951, it is now a weekly with 48 issues per year. Copyright (O 2014 American Academy of Neurology. All rights reserved. Print ISSN: 0028-3878. Online ISSN: 1526-632X.

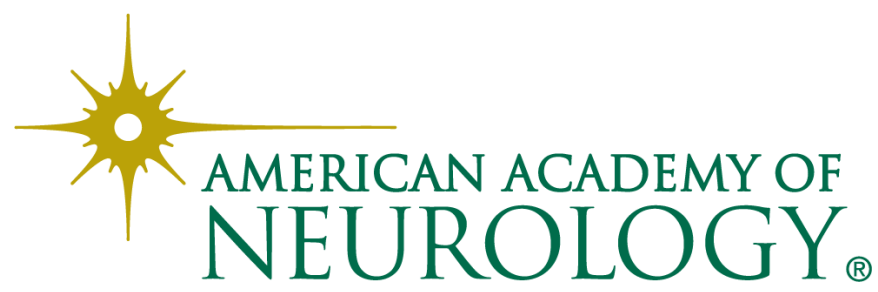

